\section{Hypoadrenalism in patients with fatigue and rheumatic disease}

\section{Dimitra Methiniti, Jennifer Hamilton, Vadivelu Saravanan, Carol Heycock, Clive Kelly}

Departments of Medicine and

Rheumatology, Queen Elizabeth Hospital, Sheriff Hill, Gateshead, UK

\section{Abstract}

Many patients with rheumatic disease complain of fatigue. Clinicians may interpret this as part of the disease process in the absence of anaemia or hypothyroidism, and sometimes respond with the empiric addition of steroids to therapy. The possibility of true hypoadrenalism is only occasionally considered, and little data exists on the frequency with which it coexists with rheumatic disease. Random serum cortisol may be requested by clinicians to help exclude hypoadrenalism as a factor in fatigue. We undertook a survey to assess how frequently this test was of clinical relevance, what was done in patients with low results, and which patients were most likely to have true adrenal failure.

All random cortisol assays requested by the members of a rheumatological team over one year were identified and the notes examined retrospectively. The indication for the request, the result, the ultimate clinical diagnosis and all prior diagnoses were recorded. Where further investigations were undertaken, these too were noted. The results were compared to those in an age and gender matched population of patients with general medical conditions (excluding endocrine disorders) for whom cortisol assays had also been requested.

Random cortisol was requested by a team of four consultants in 74 patients with a variety of rheumatic disorders over 12 months, usually because of unexplained fatigue. Among the control group of 75 medical patients, the commonest reasons for requesting cortisol assay were fatigue, low sodium and unexplained anaemia. Mean cortisol levels were significantly higher in medical patients $(512 \mathrm{nmol} / \mathrm{L})$ than those with rheumatic disease (351 $\mathrm{nmol} / \mathrm{L})[\mathrm{P}=0.04]$. The results were low $(<200$ $\mathrm{nmol} / \mathrm{L}$ ) in 14 rheumatic patients and 7 medical patients. Among these 21 individuals, synacthen tests were performed in 16 and were indicative of hypoadrenalism in 6 cases. Further investigations revealed primary hypoadrenalism in 3 patients, with tertiary adrenal suppression from oral steroids in three others. All six of these patients had underlying rheu- matic disorders, usually RA (3) or systemic lupus erythematosus (SLE) (2). None of the medical patients had an abnormal synacthen test. Fatigue in patients with rheumatic disease may be a presenting feature of hypoadrenalism. Although adrenal failure is rare in medical patients with anaemia, hyponatraemia or fatigue, patients with rheumatic disease and unexplained fatigue merit a random cortisol. If this is low, synacthen testing may be appropriate. Steroids should not be commenced empirically in such patients until hypoadrenalism has been excluded, as a significant minority will have genuine primary adrenal failure, usually due to autoimmune disease.

\section{Introduction}

Fatigue is a common complaint in the population at large. Defining medically significant fatigue can be difficult. However, certain groups of disorders are more likely to be associated with excessive fatigue and these include patients with rheumatic disease. ${ }^{1}$ Several studies have sought to define the nature of fatigue in rheumatoid arthritis (RA) by assessing patients' experiences. ${ }^{24}$ Patients rate fatigue is at least as serious as pain, ${ }^{5}$ and cited the lack of professional support for this aspect of their condition. ${ }^{6}$ Fatigue has a comparable effect to pain on the patient reported overall quality of life. .7-10 $^{57}$

Clinicians may interpret fatigue in rheumatic disorders as part of the disease process. However, the evidence for this is weak ${ }^{11}$ and conflicting. ${ }^{12,13}$ Patient perception of fatigue severity may differ from that of their attending physician. ${ }^{11}$ There is no consistent link between fatigue and either gender ${ }^{14}$ or duration of RA. ${ }^{15}$ Mood is also an important determinant of fatigue ${ }^{16,17}$ and both can vary over time. ${ }^{18,19}$ However, there is evidence that disease modifying anti rheumatic drugs and biologic agents do improve fatigue. ${ }^{20}$ Where they fail to do so, clinicians may look for evidence of anaemia or hypothyroidism. In the absence of these disorders, the empiric addition of low dose steroids is sometimes undertaken, frequently with reported short term benefit.

It is established that the endogenous steroid response to stress may be insufficient in $\mathrm{RA}^{21}$ and that this is due to a relative under performance of the hypothalamic-pituitary axis (HPA). ${ }^{22}$ Fatigue and depression are common manifestations of this and may relate to the lower cortisol levels recorded in RA, especially in early disease. ${ }^{23-25}$ Indeed, the changes in the response of the HPA are documented as also occurring early in RA. ${ }^{26-28}$ Although there is a link between fatigue and lower cortisol responses in $\mathrm{RA}$, the exact mechanism
Correspondence: Clive Kelly, Departments of Medicine and Rheumatology, Queen Elizabeth Hospital, Sheriff Hill, Gateshead NE9 65X, UK.

E-mail: clive.kelly@ghnt.nhs.uk

Key words: rheumatic disease, adrenal failure, Addison disease, rheumatoid arthritis.

Received for publication: 27 February 2009.

Revision received: 2 December 2009.

Accepted for publication: 3 December 2009.

This work is licensed under a Creative Commons Attribution 3.0 License (by-nc 3.0).

(C) Copyright D. Methiniti et al., 2009

Licensee PAGEPress, Italy

Rheumatology Reports 2009; 1:e13

doi:10.4081/rr.2009.e13

remains to be defined. ${ }^{29}$

We believe that the possibility of adrenal dysfunction as an explanation for persistent fatigue in rheumatic disease is rarely explored in every day clinical practice. Clinicians continue to underestimate the potential link between hypoadrenalism and rheumatic disorders to their patients detriment. Little data exists on the frequency with which clinical hypoadrenalism coexists with rheumatic disease, in spite of its potentially autoimmune associations. We explore the use of random serum cortisol by clinicians investigating hypoadrenalism as a potential contributory factor in fatigue. We undertook a survey to assess how frequently this test was of clinical value, and in which circumstances it was most likely to yield evidence of hypoadrenalism.

\section{Materials and Methods}

We assessed the use of cortisol assays by one medical team with four consultant members over a calendar year. The physicians in the team are all rheumatologists and serve a population of 300,000 in the North East of England. All random cortisol assays requested by the team were identified through the biochemistry laboratory database and the case notes pertaining to these patients were obtained and examined retrospectively. We collected demographic data on patients' age and gender. The indication for the request, cortisol results, timing of samples and subsequent investigations, together with the ultimate clinical diagnosis and all prior diagnoses were recorded. The patients were divided into two groups: those with rheumatic disease and those with other medical disorders, excluding known endocrine disease. These two groups were then compared to assess mean cortisol levels, numbers of patients with low random 
cortisol results and the outcome of subsequent investigations and ultimate diagnoses. Students t test was used for comparing cortisol values between groups, while the number of patients with abnormal adrenal function in each group was compared using $\chi^{2}$-testing.

\section{Results}

Random cortisol was requested by for 74 patients with a variety of rheumatic disorders over 12 months, usually because of unexplained fatigue (68) or occasionally because of unexplained anaemia. ${ }^{6}$ The indications coexisted in two patients. The group was predominantly female (68\%) with a mean age of 61 years. Most patients had RA (60\%), although connective tissue disease (22\%) and chronic pain (18\%) were also represented. Cortisol was requested in 75 patients with other medical disorders presenting with fatigue, ${ }^{48}$ hyponatraemia $^{22}$ or unexplained anaemia. ${ }^{5}$ The group was again largely female (62\%) with a mean age of 64 years. Multiple underlying diagnoses were recorded. There were no differences between the groups in terms of their age and gender mix.

Timing of samples varied widely, with most patients having blood taken during the working day. Rather more medical patients had samples taken out of hours in the evening, leading to a mean difference in sample times between the groups of 90 minutes. In spite of this, mean cortisol levels were significantly lower in patients with rheumatic disease (369 $\pm 103 \mathrm{nmol} / \mathrm{L}$ ) than in those with medical conditions $(515 \pm 122 \mathrm{nmol} / \mathrm{L}) \quad[\mathrm{P}=0.04]$. The results were low $(<200 \mathrm{nmol} / \mathrm{L})$ in 14 rheumatic patients and 7 medical patients. The indications for checking cortisol in these 21 patients are shown in Figure 1. Among these 21 individuals, repeat cortisol performed at 9 am was normal in 5 patients and further investigations were not performed. These patients had their initial samples obtained between 14.00 and 17.00 hours and it was felt that these may have been low as a result of diurnal variation rather than adrenal dysfunction.

Synacthen tests were undertaken in the remaining 16 patients. A normal response to ACTH was recorded in 10 patients with a rise in excess of $250 \mathrm{nmol} / \mathrm{L}$ cortisol following the injection. Two of these patients had taken oral prednisone until recently ( 6 and 8 weeks earlier, respectively). In a further 3 patients the response to ACTH was blunted with rises of between 100-250 $\mathrm{nmol} / \mathrm{L}$ cortisol following injection. Adrenal antibodies were absent in all three and each had been on oral prednisone at a dose of 5-10 mg daily until a week prior to the test, when it had been replaced with dexamethasone. It was felt that these patients had

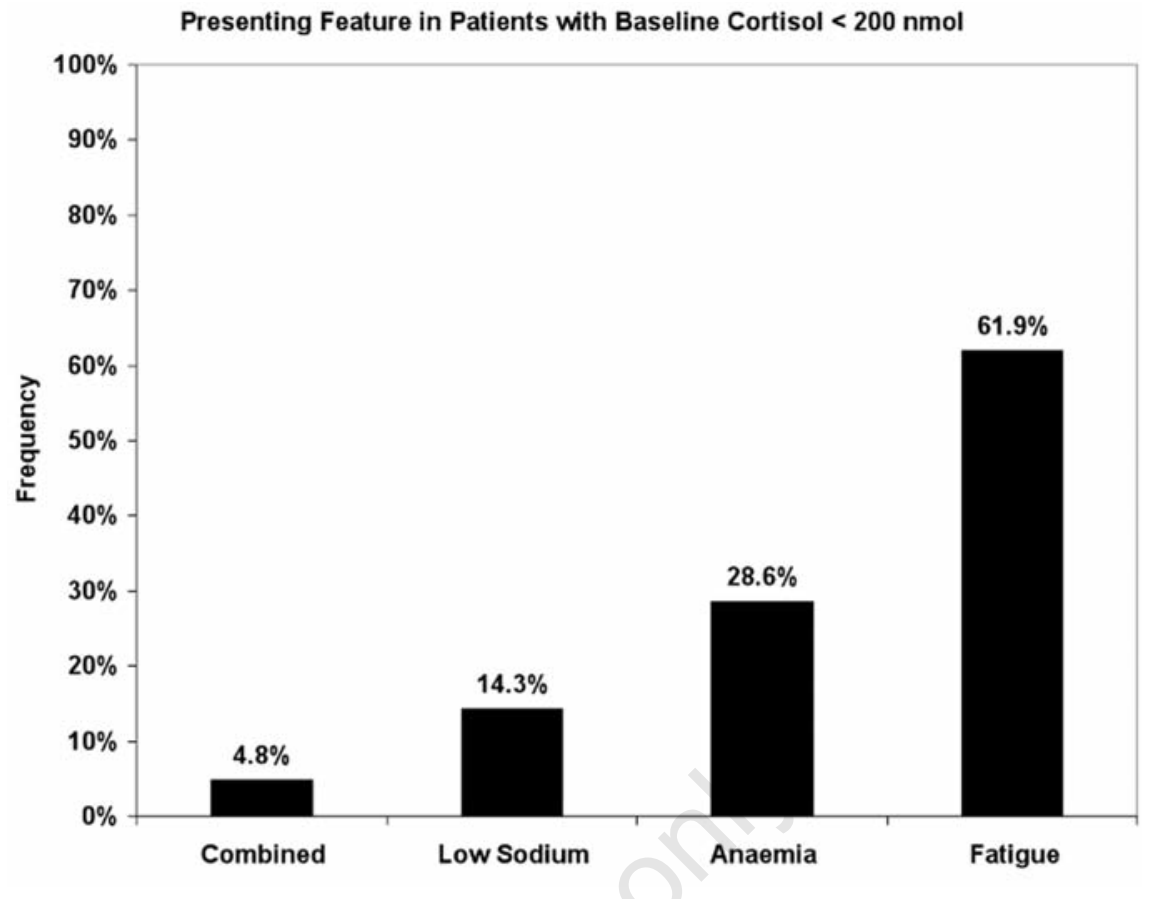

Figure 1. To show the indication for assay in 21 patients with low cortisol levels.

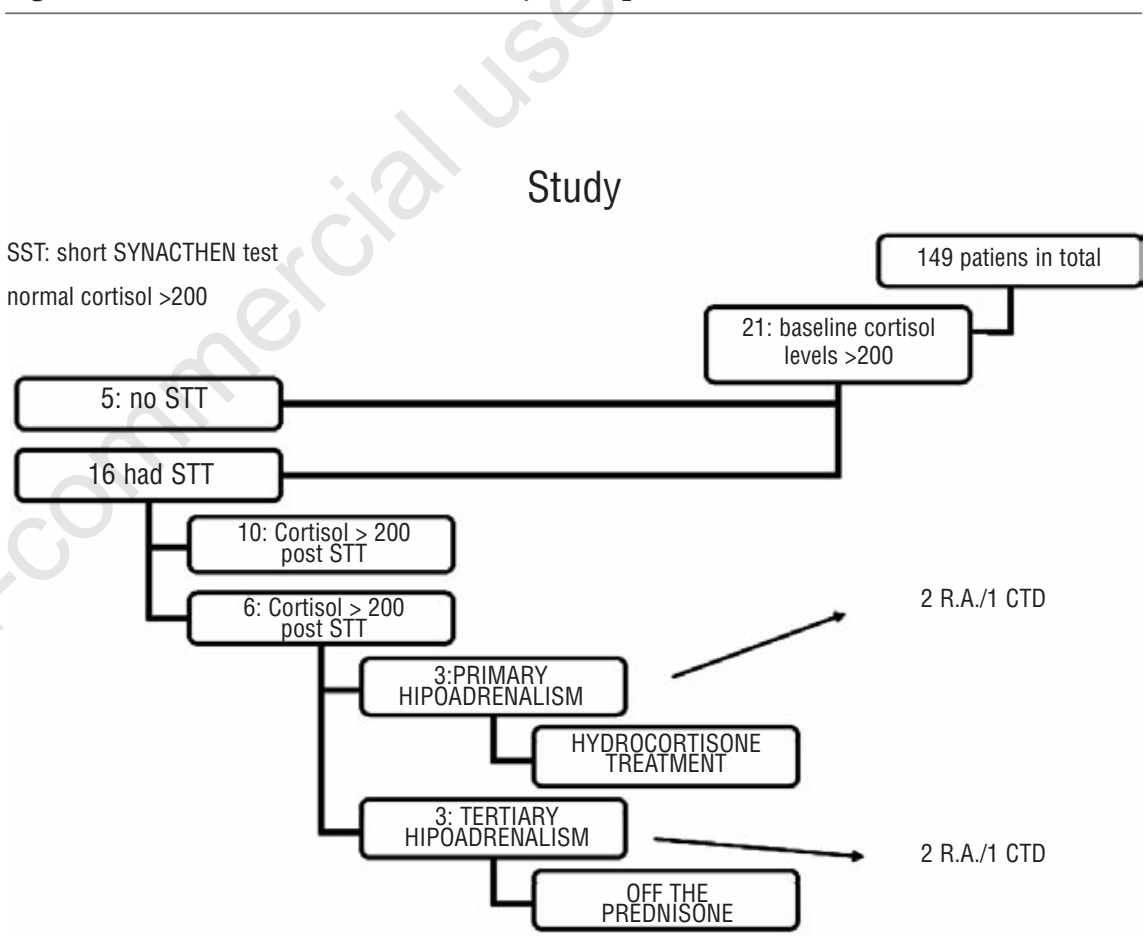

Figure 2. To show flow of patients undergoing random cortisol assay and subsequent investigations.

tertiary hypoadrenalism as a consequence of suppression of normal adrenal - pituitary axis function by long term steroid therapy. Oral steroids were reduced very gradually and eventually stopped in each patient.

In the remaining three patients, there was no significant response to ACTH with the rise in cortisol levels being less than $100 \mathrm{nmol} / \mathrm{L}$. Circulating ACTH was elevated in each patient and two had evidence of circulating anti-adrenal antibodies. A diagnosis of primary hypoadrenalism was made in each case, likely to be of autoimmune origin as no other cause could be established. Each patient was commenced on physiological doses of hydrocortisone with rapid relief of fatigue. Each of these three individuals was able to return to work and rated their improvement as 'very good' [2] or excel- 
lent. ${ }^{1}$ Figure 2 shows the cascade of tests and diagnosis in our study.

All six patients with adrenal dysfunction came from the group with underlying rheumatic disease - RA in 3, systemic lupus erythematosus (SLE) in 2 and mixed connective tissue disease (MCTD) in 1. Primary adrenal failure (Addisons disease) was present in two patients with RA and one with SLE. Among the seven patients with an underlying medical diagnosis, four had normal 9 am cortisol levels and synacthen tests were normal in the remaining three. Adrenal disease was significantly more prevalent in the patients with rheumatic disease $[\mathrm{P}=0.03]$.

\section{Discussion}

Fatigue is a well recognised feature of many rheumatic diseases where it has been shown to be equivalent to that experienced by patients with cancer..$^{30}$ Validated quantification techniques ${ }^{31,32}$ have also demonstrated that levels of fatigue are similar in a variety of rheumatic diseases including $\mathrm{RA},{ }^{33} \mathrm{SLE},{ }^{34}$ ankylosing spondylitis ${ }^{35}$ and scleroderma. ${ }^{36}$ Physical factors consequent on coexisting disease have not been addressed in these publications and we feel that clinicians should be aware of potentially reversible causes of fatigue in rheumatic disease.

Adrenal underactivity may produce a variety of symptoms but paramount among these is fatigue ${ }^{37}$ Persistent anaemia of chronic disease is also reported with primary adrenal failure, the most frequent causes of which is auto immune adrenalitis. ${ }^{38}$ The response to physiological doses of hydrocortisone is dramatic and sustained, making it an important diagnosis not to miss. Checking an early morning cortisol in these patients may prove valuable, and a synacthen test should be considered in those patients with a low level. The use of empiric oral prednisone for fatigue in RA and other rheumatic diseases should be reconsidered in this context, as it may mask the features of Addison disease and delay or obscure its diagnosis.

The impaired cortisol response associated with early RA can be reversed by the appropriate use of early steroids. ${ }^{39}$ Down regulation of glucocorticoid receptors has been reported to occur early in $\mathrm{RA}^{40}$ and has been shown to be reversible by the use of physiological doses of steroid. ${ }^{41}$ A commensurate improvement in symptoms of fatigue and wellbeing were reported shortly after steroids became available for the treatment of RA, ${ }^{42}$ and their benefit has been compared to that achieved by more recent and specific therapy with the anti-TNF agents in RA. ${ }^{43}$

Our data shows that cortisol is more likely to be low in patients with fatigue if they have rheumatic disease. Such links have been hypothesised but infrequently reported, although a relationship between other rheumatic disorders and primary adrenal failure has been described. ${ }^{44,45}$ Adrenal failure secondary to pituitary disease is relatively rare and unsurprisingly, we found no cases of this in our study. However we did detect three patients who had been on oral steroids long term and who developed tertiary adrenal insufficiency, resulting from inadequate $\mathrm{CRH}$ release from the pituitary with a resultant decrease in ACTH release.

Cessation of steroid therapy abruptly is a well recognised cause, ${ }^{46}$ although even a gradual reduction in steroid dose needs to be undertaken with caution. In one of our patients, oral prednisone had been taken at the dose of $10 \mathrm{mg}$ daily for several years and although the dose was reduced at the rate of 1 mg each month, hypoadrenalism subsequently ensued. It is important to minimise the use of long term oral steroids in established RA as recently recommended by $\mathrm{NICE}^{47}$ For those established on oral steroids, weaning must be performed slowly with advice to increase the dose if an intercurrent illness develops. Hazards associated with long term steroids are multiple and other undesirable side effects in RA include osteoporosis ${ }^{48}$ and increased morbidity and mortality from chest infections. ${ }^{49}$

In conclusion, fatigue in patients with rheumatic disease may be a presenting feature of hypoadrenalism. Although adrenal failure is rare in medical patients with anaemia, hyponatraemia or fatigue, patients with rheumatic disease and unexplained fatigue merit a random cortisol. If this is low, synacthen testing is mandatory. Steroids should not be commenced empirically in such patients until hypoadrenalism has been excluded, as a significant minority will have genuine primary adrenal failure, often due to autoimmune disease. Even when patients with rheumatic disease are commenced on oral steroids, this should be in the lowest effective dose and, where possible, for a limited time period.

\section{References}

1. Kirwan J, Minnock P, Adebajo A et al. Patient perspective: fatigue as a recommended patient centred outcome measure in rheumatoid arthritis. J Rheumatol 2007; 34:1174-7.

2. Hewlett S, Cockshott Z, Byron M et al. Patients' perceptions of fatigue in rheumatoid arthritis: overwhelming, uncontrollable, ignored. Arthritis Rheum 2005;53:697-702.

3. Tack BB. Fatigue in rheumatoid arthritis: conditions, strategies, and consequences.
Arthritis Care Res 1990;3:65-70.

4. Repping-Wuts H, Uitterhoeve R, van Riel P, van Achterberg T. Fatigue as experienced by patients with rheumatoid arthritis (RA): a qualitative study. Int J Nurs Stud 2008;45:995-1002.

5. Katz PP. The stresses of rheumatoid arthritis: appraisals of perceived impact and coping efficacy. Arthritis Care Res 1998;11:922.

6. Wolfe F, Hawley DJ, Wilson K. The prevalence and meaning of fatigue in rheumatic disease. J Rheumatol 1996;23:1407-17.

7. Suurmeijer T, Waltz M, Moum T et al. Quality of life profiles in the first years of rheumatoid arthritis: results from the EURIDISS longitudinal study. Arthritis Rheum 2001;45:111-21.

8. Rupp I, Boshuizen HC, Jacobi CE et al. Impact of fatigue on health-related quality of life in rheumatoid arthritis. Arthritis Rheum 2004;51:578-85.

9. Minnock P, Bresnihan B. Pain outcome and fatigue levels reported by women with established rheumatoid arthritis. Arthritis Rheum 2004;50:S471(1198).

10. Hewlett S, Carr M, Ryan S et al. Outcomes generated by patients with rheumatoid arthritis: how important are they? Musculoskeletal Care 2005;3:131-42.

11. Swain MG. Fatigue in chronic disease. Clin Sci (Lond) 2000;99:1-8.

12. Pollard LC, Choy EH, Gonzalez J et al. Fatigue in rheumatoid arthritis reflects pain, not disease activity. Rheumatology (Oxford) 2006;45:885-9.

13. Treharne GJ, Lyons AC, Hale ED et al. Predictors of fatigue over 1 year among people with rheumatoid arthritis. Psychol Health Med 2008;13:494-504.

14. Huyser BA, Parker JC, Thoreson R et al. Predictors of subjective fatigue among individuals with rheumatoid arthritis. Arthritis Rheum 1998;41:2230-7.

15. Barlow JH, Cullen LA, Rowe IF. Comparison of knowledge and psychological wellbeing between patients with a short disease duration ( $\leq 1$ year) and patients with more established rheumatoid arthritis ( $\geq 10$ years duration). Patient Educ Couns 1999;38:195-203.

16. Zautra AJ, Fasman R, Parish BP, Davis MC. Daily fatigue in women with osteoarthritis, rheumatoid arthritis, and fibromyalgia. Pain 2007;128:128-35.

17. Fifield J, McQuillan $\mathrm{J}$, Tennen $\mathrm{H}$ et al. History of affective disorder and the temporal trajectory of fatigue in rheumatoid arthritis. Ann Behav Med 2001;23:34-41.

18. Stone AA, Broderick JE, Porter LS, Kaell AT. The experience of rheumatoid arthritis pain and fatigue: examining momentary reports and correlates over one week. Arthritis Care Res 1997;10:185-93. 
19. Scharloo M, Kaptein AA, Weinman JA et al. Predicting functional status in patients with rheumatoid arthritis. J Rheumatol 1999;26:1686-93.

20. Strand V, Singh JA. Improved health-related quality of life with effective diseasemodifying antirheumatic drugs: evidence from randomized controlled trials. Am J Manag Care 2007;13:S237-51.

21. Neeck G, Federlin K, Graef V et al. Adrenal secretion of cortisol in patients with rheumatoid arthritis. J Rheumatol 1990; 17:24-9.

22. Masi AT, Chrousos GP. Hypothalamic-pituitary-adrenal axis function in rheumatoid arthritis. J Rheumatol 1996; 23:577-81.

23. Smith TW, Peck JR, Ward JR. Helplessness and depression in rheumatoid arthritis. Health Psychol 1990;9:377-89.

24. Smedstad LM, Moum T, Vaglum P, Kvien TK. The impact of early rheumatoid arthritis on psychosocial distress. Scand J Rheumatol 1996;25:377-82.

25. Evers AWM, Kraaimaat FW, Geenen R, Bijlsma JWJ. Determinants of psychological distress and its course in the first year after diagnosis in rheumatoid arthritis patients. J Behav Med 1997;20:489-504.

26. Cutolo M. The role of the hypothalamuspituitary-adrenocortical and -gonadal axis in rheumatoid arthritis. Clin Exp Rheumatol 1998:16:3-6.

27. Cutolo M, Foppiani L, Prete C et al. Hypothalamic-pituitary-adrenocortical axis function in premenopausal women with rheumatoid arthritis not treated with glucocorticoids. J Rheumatol 1999;26:2828.

28. Dekkers JC, Geenen R, Godaert GL et al. Experimentally challenged reactivity of the hypothalamic pituitary adrenal axis in patients with recently diagnosed rheumatoid arthritis. J Rheumatol 2001;28:1496504.

29. Jessop DS, Harbuz MS. A defect in cortisol production in rheumatoid arthritis: why are we still looking? Rheumatology
(Oxford) 2005;44:1097-100

30. Thombs BD, Bassel M, McGuire L et al. A systematic comparison of fatigue levels in systemic sclerosis with general population, cancer and rheumatic disease samples. Rheumatology 2008;47:1559-63.

31. Hewlett S, Hehir M, Kirwan JR. Measuring fatigue in rheumatoid arthritis: a systematic review of scales in use. Arthritis Rheum 2007;57:429-39.

32. Wolfe F. Fatigue assessments in rheumatoid arthritis: comparative performance of visual analog scales and longer fatigue questionnaires in 7760 patients. J Rheumatol 2004;31:1896-902.

33. Rupp I, Boshuizen HC, Jacob CE, et al. Impact of fatigue in health related quality of life in rheumatoid arthritis. Arthritis Rheum 2004;51: 578-85

34. Da Costa D, Dritsa M, Bernatsky S et al. Dimensions of fatigue in systemic lupus erythematosus: relationship to disease status, behavioural and psychosocial factors. J Rheumatol 2006;38:1282-8.

35. van Tubergen A, Coenen J, Landewe R et al. Assessment of fatigue in patients with Ankylosing Spondylitis; a psychometric analysis. Arthritis Rheum 2002;47:8-16.

36. Burke CW. Adrenocortical insufficiency. Clin Endocrinol Metab 1985;14:947.

37. Zelissen PM, Bast EJ, Croughs RJ. Associated autoimmunity in Addison's disease. J Autoimmun 1995;8:121

38. Kasperlik-Zaluska AA, Migdalska B, Czarnocka B, et al. Association of Addison's disease with autoimmune disorders - a long-term observation of 180 patients. Postgrad Med J 1991; 67:984.

39. Gudbjornsson BB, Skogseid BK, Oberg K et al. ACTH secretion but impaired cortisol response in patients with active RA. Effect of glucocorticoids. J Rheumatol 1996;23: 596-602.

40. van Everdingen AA, Huisman AM, Wenting MJ, et al. Down regulation of glucocorticoid receptors in early-diagnosed rheumatoid arthritis. Clin Exp Rheumatol
2002;20:463-8.

41. Huisman AM, Siewertsz van Everdingen AA, Wenting MJ et al. Glucocorticoid receptor up-regulation in early rheumatoid arthritis treated with low dose prednisone or placebo. Clin Exp Rheumatol 2003;21: 217-20.

42. The Joint Committee of the Medical Research Council and Nuffield Foundation on Clinical Trials of Cortisone, ACTH, and Other Therapeutic Measures in Chronic Rheumatic Diseases. A comparison of prednisolone with aspirin or other analgesics in the treatment of rheumatoid arthritis. Ann Rheum Dis 1959;18:173-187.

43. Wolfe F, Michaud K. Fatigue, rheumatoid arthritis, and anti-tumor necrosis factor therapy: an investigation in 24,831 patients. J Rheumatol 2004;31:2115-20.

44. Asherson RA, Hughes GRV. Recurrent deep vein thrombosis and Addison's disease in "primary" antiphospholipid syndrome. J Rheumatol 1989;16:378.

45. Trence DL, Morley JE, Handwerger BS. Polyglandular autoimmune syndromes. Am J Med 1984;77:107.

46. Cronin CC, Callaghan N, Kearney PJ, et al. Addison disease in patients treated with glucocorticoid therapy. Arch Intern Med 1997;157:456

47. NICE guidelines 'Rheumatoid arthritis: the management of rheumatoid arthritis in adults'. http://www.nice.org.uk/guidance/index.jsp?action=byID\&0=12131.

48. Kelly CA, Bartholomew P, Lapworth A et al. Peripheral bone density in patients with rheumatoid arthritis and factors which influence it. Eur J Intern Med 2002;13: 423-7.

49. Coyne P, Hamilton J, Heycock C et al. Acute lower respiratory tract infections in patients with rheumatoid arthritis.J Rheumatology 2007;34:1832-7. 